Koji Fujii • Hiroaki Senju • Kanako Yoshida

Kazumasa Sekiguchi • Kazuhiko Imaizumi

Kentaro Kasai · Hajime Sato

\title{
Multiplex PCR amplification of TH01, D9S304, and D3S1744 loci
}

\begin{abstract}
A multiplex typing method of the tetrameric short tandem repeat (STR) loci TH01, D9S304, and D3S1744 was developed. The allelic ladder included alleles 6-11 (80-100 bp) and 9.3 (95bp) for TH01, alleles 6-15 (125-161 bp) for D9S304, and alleles 13-22 (174-210bp) for D3S1744. The observed heterozygosity of D9S304 was 0.851 . The combined discrimination power of the three loci was 0.991 .
\end{abstract}

Key words Forensic $\cdot$ DNA typing $\cdot$ STR $\cdot$ Multiplex PCR · TH01 $\cdot$ D9S304 $\cdot$ D3S1744

\section{Introduction}

Short tandem repeat (STR) loci consist of tandemly repeated sequences of two to five base pairs. Their abundance, hypervariability, and amenability to co-amplification by multiplex polymerase chain reaction (PCR) make them ideal DNA markers for use in individual identification (Edwards et al. 1991; Kimpton et al. 1994; Kimpton et al. 1996; Micka et al. 1996; Xiao et al. 1998; Lazaruk et al. 1998; Lins et al. 1998). Here, we describe a method for multiplex PCR of TH01 (Edwards et al. 1991), D9S304, and D3S1744 (Neuweiler et al. 1996; Perlee et al. 1996).

K. Fujii $(\bowtie) \cdot$ H. Senju $\cdot$ K. Yoshida $\cdot$ K. Kasai

Third Medico-Legal Section, National Research Institute of Police

Science, 6-3-1 Kashiwanoha, Kashiwa-shi, Chiba 277-0882, Japan

Tel. +81-471-35-8001; Fax +81-471-33-9153

e-mail: fujii@nrips.go.jp

K. Sekiguchi

Second Medico-Legal Section, National Research Institute of Police

Science, Kashiwa, Japan

K. Imaizumi

First Medico-Legal Section, National Research Institute of Police

Science, Kashiwa, Japan

H. Sato

Identification Center, National Research Institute of Police Science,

Kashiwa, Japan

\section{Materials and methods}

Three autosomal tetrameric STR loci (TH01, D9S304, and D3S1744) were used in this study. Their sequence data and their chromosomal locations were quoted from the Genome data base (Accession numbers TH01, D00269; D9S304, G08747; D3S1744, G08246).

Multiplex PCR was performed using 2-50ng of genomic DNA in a $50-\mu l$ reaction volume. The reaction mix contained $15 \mathrm{mM}$ Tris- $\mathrm{HCl}(\mathrm{pH} 8.0), 50 \mathrm{mM} \mathrm{KCl}, 1.5 \mathrm{mM}$ $\mathrm{MgCl}_{2}, 0.2 \mathrm{mM}$ dNTPs, $0.16 \%$ bovine serum albumin (BSA), 0.1 U/ $\mu$ l Ampli Taq Gold (PE Biosystems, Foster City, CA, USA), and $0.25 \mu \mathrm{M}$ each primer (Table 1). The thermal cycle was initial denaturing at $95^{\circ} \mathrm{C}$ for $11 \mathrm{~min}$, followed by 26 cycles of denaturing at $94^{\circ} \mathrm{C}$ for $1 \mathrm{~min}$, annealing at $56^{\circ} \mathrm{C}$ for $1 \mathrm{~min}$, and extension at $72^{\circ} \mathrm{C}$ for $1 \mathrm{~min}$. A final extension was performed at $60^{\circ} \mathrm{C}$ for $60 \mathrm{~min}$.

The allelic ladder was constructed, mixing the PCR products of the three loci. The allelic ladder included alleles 6-11 (80-100bp) and 9.3 (95bp) for TH01, alleles 6-15 (125-161 bp) for D9S304, and alleles 13-22 (174-210bp) for D3S1744.

\section{Results and discussion}

We developed a multiplex typing system of TH01, D9S304, and D3S1744 loci for individual identification from evidential samples (Fig. 1).

The D9S304 locus was sequenced from seven homozygous samples and K562 DNA. The repeat unit of the D9S304 locus was GATA, and the sequences were identical to that deposited in the Genome Data Base.

The D3S1744 locus was sequenced from eight homozygous samples and K562 DNA. The basic repeat unit of the D3S1744 locus was GATA, as reported by Perlee et al. (1996). However, the number of TAGA flanked with GATA repeats was also variable. Five samples possessed $(\mathrm{TAGA})_{2}, \mathrm{~K} 562$ DNA possessed (TAGA) $)_{3}$, and the other 
Table 1. Primer sequences of three short tandem repeat (STR) loci

\begin{tabular}{ll}
\hline THF & 5'-CCT CCC TTA TTT CCC TCA T-3' \\
THR & 5'-CTT CCG AGT GCA GGT CAC-3' \\
D9F & 5'-CTC CAG TCT TTT TAA TAA TGA ATT-3' \\
D9R & 5'-ATA TGT GCC CAC ACA CAT CT-3' \\
D3F & 5'-GAC CAC TTC CAG TCC TCA CT-3' \\
D3R & 5'-GCC ACT GCC TCT AAA ATT GT-3'
\end{tabular}

THR, D9R, and D3R primers were labeled with 5-FAM

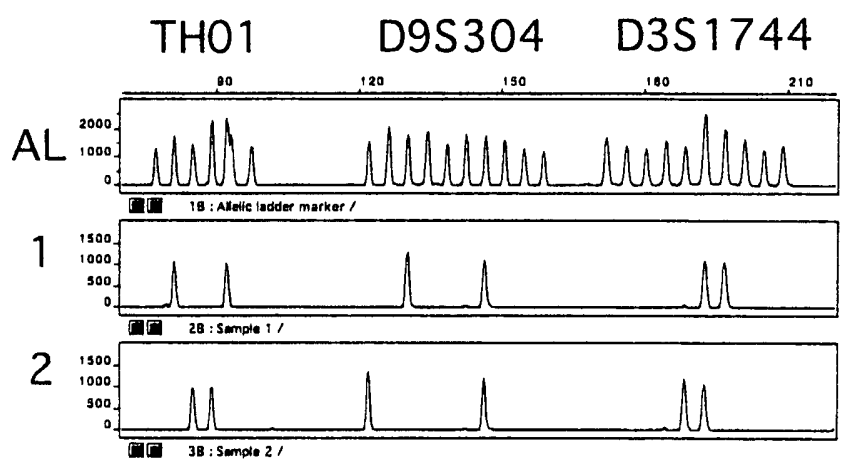

Fig. 1. Multiplex polymerase chain reaction amplification of TH01, D9S304, and D3S1744 loci. AL, Allelic ladder. 1, Sample 1, alleles 79.3 (TH01), alleles 8-12 (D9S304), and alleles 18-19 (D3S1744); 2, sample 2, alleles 8-9 (TH01), alleles 6-12 (D9S304), and alleles 17-18 (D3S1744)

three samples possessed KAKA followed by (TAGA), where $\mathrm{K}$ represents $\mathrm{G}$ or $\mathrm{T}$.

The distribution of allele frequency and the statistical properties of the D9S304 locus in a Japanese population are shown in Table 2. The observed heterozygosity of D9S304 (0.851) was slightly higher than that of TH01 (0.723 in Yoshida et al. 1996; 0.70 in Nagai et al. 1996) and that of D3S1744 (0.788 in Senju et al. 1999). The combined discrimination power of the three loci in a Japanese population was 0.991 . This value reveals that this multiplex typing method is a powerful one for individual identification.

\section{References}

Edwards A, Civitello A, Hammond HA, Caskey CT (1991) DNA typing and genetic mapping with trimeric and tetrameic tandem repeats. Am J Hum Genet 49:746-756

Kimpton C, Fisher D, Watson S, Adams M, Urquhart A, Lygo J, Gill P (1994) Evaluation of an automated DNA profiling system employing multiplex amplification of four tetrameric STR loci. Int J Legal Med 106:302-311

Kimpton CP, Oldroyd NJ, Watson SK, Frazier RRE, Johnson PE, Millican ES, Urquhart A, Sparkes BL, Gill P (1996) Validation of highly discriminating multiplex short tandem repeat amplification
Table 2. Allele frequencies of D9S304 locus in a Japanese population

$n=114$

D9S304

Allele Frequency

\begin{tabular}{lll}
\hline 6 & 0.066 & \\
7 & 0.018 & \\
8 & 0.355 & \\
9 & 0.053 & \\
10 & 0.079 & \\
11 & 0.075 & \\
12 & 0.167 & \\
13 & 0.118 & \\
14 & 0.061 & \\
15 & 0.009 & 0.851 \\
\hline Observed heterozygosity & & 0.809 \\
Expected heterozygosity & & 0.934 \\
Discrimination power & & \\
Polymorphism information content & &
\end{tabular}

systems for individual identification. Electrophoresis 17:12831293

Lazaruk K, Walsh PS, Oaks F, Gilbert D, Rosenblum BB, Menchen S, Scheibler D, Wenz HM, Holt C, Wallin J (1998) Genotyping of forensic short tandem repeat (STR) systems based on sizing precision in a capillary electrophoresis instrument. Electrophoresis 19:86-93

Lins AM, Micka KA, Sprecher CJ, Taylor JA, Bacher JW, Rabbach DR, Bever RA, Creacy SD, Schumm JW (1998) Development and population study of an eight-locus short tandem repeat (STR) multiplex system. J. Forensic Sci 43:1168-1180

Micka KA, Sprecher CJ, Lins AM, Comey CT, Koons BW, Crouse C, Endean D, Pirelli K, Lee SB, Duda N, Ma M, Schumm JW (1996) Validation of multiplex polymorphic STR amplification sets developed for personal identification applications. J Forensic Sci 41:582590

Nagai A, Yamada S, Watanabe Y, Bunai Y, Ohya I (1996) Analysis of STR loci HUMF13A01, HUMFXIIIB, HUMLIPOL, HUMTH01, HUMTPOX and FUMVWAF31 in a Japanese population. Int $\mathbf{J}$ Legal Med 109:34-36

Neuweiler J, Perlee L, Venturini J, Balazs I (1996) Properties of an STR multiplex marker system suitable for paternity and forensic determinations. In: Carracedo A, Brinkmann B, Bär W (eds) Advances in forensic haemogenetics 6. Springer-Verlag, Berlin Heidelberg, pp 148-150

Perlee L, Neuweiler J, Balazs I (1996) Analysis of sequence variations in the alleles from three STR loci. In: Carracedo A, Brinkmann B, Bär W (eds) Advances in forensic haemogenetics 6. Springer-Verlag, Berlin Heidelberg, pp 52-54

Senju H, Fujii K, Yoshida K, Sekiguchi K, Kasai K, Sato H (1999) Forensic assessment of D3S1744 locus typing kit (in Japanese). Reports of the National Research Institute of Police Science Research on Forentic Science 52:27-32

Xiao FX, Gilissen A, Cassiman JJ, Decorte R (1998) Quadruplex fluorescent STR typing system (HUMVWA, HUMTH01, D21S11 and HPRT) with sequence-defined allelic ladders. Identification of a new allele at D21S11. Forensic Sci Int 94:39-46

Yoshida K, Kasai K, Senju H, Sekiguchi K, Mizuno N, Sakai I, Sato H, Seta S (1996) TH01 typing of Japanese population and its application to evidential samples. Jpn J Sci Tech Iden 1:33-37 